\title{
CENTROS DE PRODUCCIÓN DE CERÁMICA FINA DE MESA EN EL ALTO GUADALQUIVIR: CUATRO DÉCADAS DE INVESTIGACIÓN EN EL COMPLEJO ALFARERO DE LOS VILLARES DE ANDÚJAR (JAÉN)
}

\author{
Centers of production of fine ceramic in the high Guadalquivir: \\ four decades of investigation in the complex potter of villares \\ (Andújar-Jaén, Spain)
}

\author{
M. ${ }^{a}$ Isabel Fernández García*
}

Recibido el 17 de diciembre de 2010. Aceptado el 22 de febrero de 2011

\begin{abstract}
Resumen. La finalidad de este estudio es la valoración de la investigación en los alfares isturgitanos (Isturgi, Los Villares de Andújar, Jaén, España), en el pasado el presente y el futuro.

Palabras clave: Hispania, Baetica, Isturgi, centro de producción, cerámicas.
\end{abstract}

\begin{abstract}
The aim of the study is the valuation of the research in the isturgitanian officinae (Isturgi, Los Villares de Andújar, Jaén, Spain) during the past, the present and the future. Key Words: Hispania, Baetica, Isturgi, center of production, ceramics.
\end{abstract}

\section{INTRODUCCIÓN}

Kant en su introducción a la Crítica de la Razón Pura decía "No hay duda que todo conocimiento comienza con la experiencia...." Independientemente de la connotación que dicha sentencia tuviese para los empiristas o los racionalistas, quisiera aplicarla, lato sensu, en este caso concreto, a las investigaciones desarrolladas en el complejo alfarero ubicado en la antigua ciudad de Isturgi (Los Villares de Andújar). En este sentido, resaltar la experiencia de treinta y ocho años de trabajo relativos al yacimiento, con tres generaciones de investigadores y dos grandes proyectos científicos vinculados de facto al mismo: uno denominado "Romanización del Alto
Guadalquivirn dirigido por M. Sotomayor (1972-1979) y por M. Roca Roumens (1979-1994) y otro, aprobado en 1995 por la Dirección General de Bienes Culturales de la Junta de Andalucía bajo el título de "Isturgi romana y su territorio: la producción de terra sigillata y su difusión» actualmente activo y dirigido por la que suscribe (fig. 1).

A su vez, indirectamente el yacimiento ha sido objeto de atención en una serie de proyectos de investigación competitivos, lo que ha redundado en un mayor grado de conocimiento sobre determinados aspectos de carácter productivo y comercial'.

La provincia de Jaén cuenta con un riquísimo patrimonio arqueológico, siendo la época ibérica a la que se ha de-

\footnotetext{
* Universidad de Granada. mifernan@ugr.es.

"Catalogación y análisis histórico de la prosopografía romana y visigoda de la Hispania meridional y Visigoda" (C.I.C.C.Y.T. PB88-0476) I.P. C. González Román (UGR); «Estructuras de producción y comercialización de la vajilla de mesa romana y su contexto social y económico» (D.G.C.Y.T. PB96 0390) y «Comercio, distribución y adquisición de la vajilla de mesa romana en el Mediterráneo Occidental en época Tardo Republicana y Alto imperial» (D.G.C.Y.T. BHA2000 0723) I.P. M. Roca Roumens (U.B.); "Estructuras de producción en el artesanado en la antigüedad en Andalucia Oriental» (Plan Propio Investigación 2003 Universidad de Granada) y «Ciudad y tradiciones productivas: comercio, distribución y consumo" (HUM2007-64460/HIST), I.P. Ma Isabel Fernández García (UGR).
} 


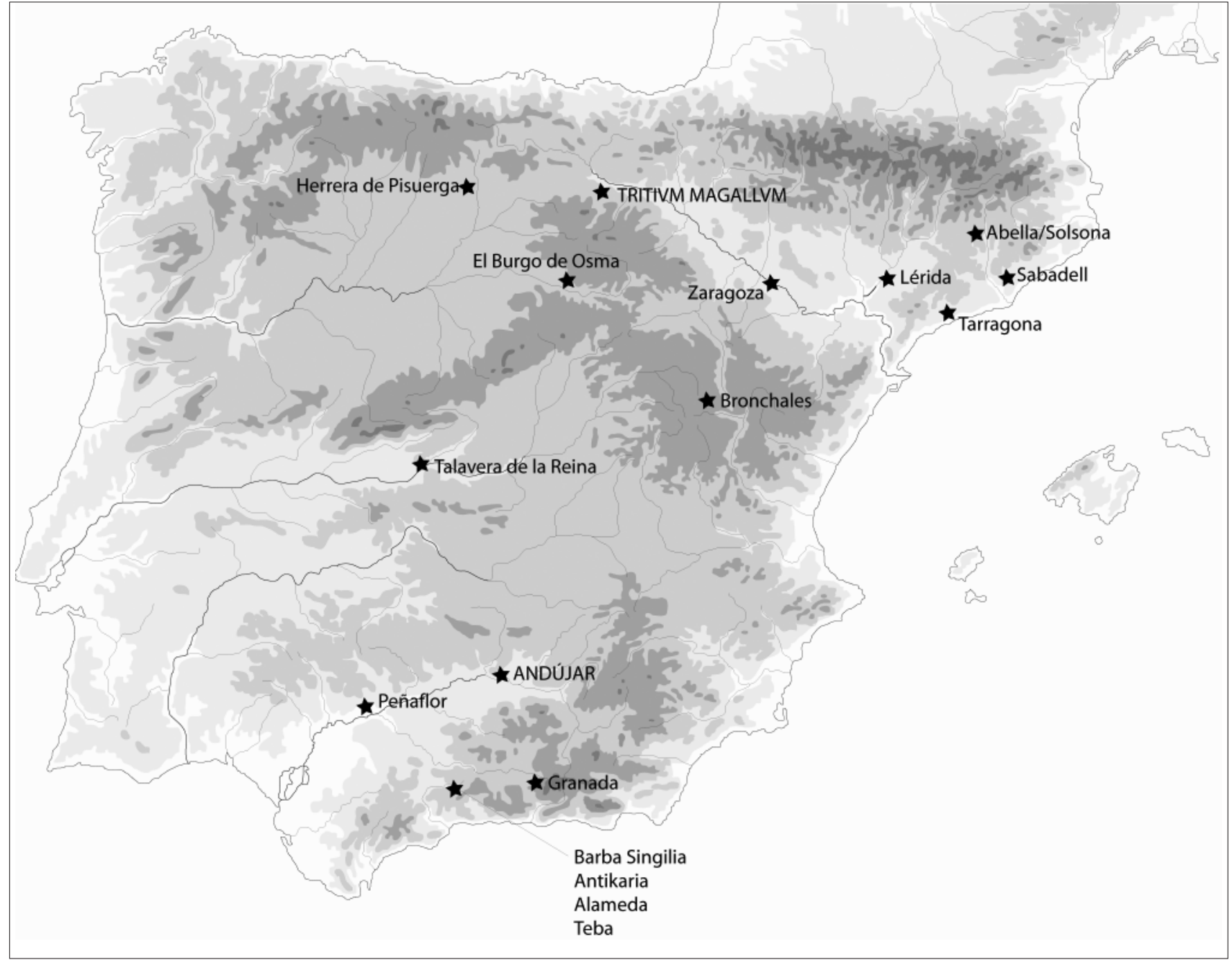

FIgURA 1. Centros productores de terra sigillata hispánica.

dicado especial atención al ser una de las líneas prioritarias de la Universidad de Jaén. Si bien, paulatinamente, se van desarrollando importantes estudios sobre la etapa romana, ningún proyecto cuenta, hasta el presente, con la capacidad científica del centrado en la ciudad de Isturgi. Realmente pocos yacimientos han tenido la fortuna de gozar de la consideración investigadora que posee el ubicado en Los Villares de Andújar. Ello explica el considerable número de publicaciones que se han generado, en su mayoría, orientadas al estudio cronotipológico de su cultura material (v. anexo I en Fernández García y Morales de la Cruz 2007).

\section{PASADO Y PRESENTE DE LAS INVESTIGACIONES EN EL COMPLEJO ISTURGITANO.}

Superada la controversia suscitada antaño, por motivos puramente religiosos, sobre la localización de los topónimos Isturgi e Iliturgi, actualmente no existe ninguna duda, en la historiografía moderna, acerca de la ubicación de lsturgi en Los Villares de Andujar y de Iliturgi en Cerro de Máquiz (Mengibar), al proceder de ambos núcleos la mayor parte de la documentación epigráfica en algunos de cuyos epígrafes se alude al topónimo Isturgi como Municipium o como Res Publica y a Iliturgi como Forum Iulium (González Román y Mangas Manjarres 1991).

La primera mención sobre el asentamiento nos la proporciona Plinio (Nat. Hist. III, 3, 10), quién incluye a Isturgi entre los núcleos del Conventus Cordubensis:

Celeberrima inter hunc et oceani oram in mediterraneo Segida quae Augurina cognominatur, Vlia quae Fidentia, Vrgao quae Alba, Ebora quae Cerialis, lliberri quod Florentini, Ilipula quae Laus, Artigi quod lulienses, Vesci quod Faventia, Singili, Ategua, Arialdunum, Agla Minor, Baebro, Castra Vinaria, Cisimbrium, Hippo Nova, Ilurco, Osca, Oscua, Sucaelo, Vnditanum, Tucci Vetus, omnia Bastetaniae vergentis ad mare. conventus vero Cordubensis circa flumen ipsum Ossigi quod cognominatur Latonium, Iliturgi quod Forum Iulium, Ipra, Isturgi quod Triumphales, $\mathrm{V}$ cia et $\mathrm{X}$ p. remotum in mediterraneo Obulco quod Pon- 
tificense appellatur, mox Ripa, Epora foederatorum, Sacili Martialium, Onuba et dextra Corduba colonia Patricia cognomine, inde primum navigabili Baete oppida Carbula, Detumo, fluvius Singilis, eodem Baetis latere incidens. (Ed. Mayhoff, 1906, 234-235).

"Las poblaciones más conocidas en el interior, entre éste (sc. el río Betis) y la costa, son: Ségida, que es llamada Augurina, Ulia Ilamada Fidencia, Urgao llamada Alba, Ébora llamada Ceriale, Ilíberri Ilamada Florentini, Ilipula Ilamada Laus, Ártigi, Ilamada lulense, Vesci llamada Favencia, Síngili, Ategua, Arialduno, Agla Menor, Bebro, Castra Vinaria, Cisimbrio, Hipo Nova, Ilurco, Osca, Oscua, Sucelo, Unditano y Tucci Vieja, todas pertenecientes a la Bastetania que da al mar. Por su parte, pertenecen al convento cordubense, en las inmediaciones del propio rio, Osigi, que es llamada Latonio, Iliturgi llamada Foro Julio, Ipra, Isturgi llamada Triumfale, Ucia y, alejado catorce mil pasos al interior, Obulco, que también se llama Pontificense; en seguida están Ripa, Epora, una de las confederadas, Sácili Marcialio, Onuba y a la derecha Córduba, colonia de nombre Patricia; a partir de aquí, cuando el Betis es por primera vez navegable, están las plazas de Cárbula y Detumo, y el río Singilis, que desemboca en esta misma parte del Betis» (Trad. de A. Ibáñez Chacón).

Una nueva referencia al lugar nos la proporciona una ley promulgada por Sisebuto:

Flavius Sisebutus rex.

"Sanctissimis ac beatissimis Agapio, Cicilio, item Agapio episcopis sive iudicibus ibidem institutis, similiter et reliquis sacerdotibus vel iudicibus in territoria Barbi, Aurgi, Sturgi, Iliturgi, Viatia, Tuia, Tutugi, Egabro et Epargo consistentibus. Dum late constitutionis auctoritas a domino et praedecessore nostro Reccaredo rege sufficere poterat, ut mancipia cristiana nullatenus in Aebreorum iure manerent obnoxia, si in postmodum contra iustitie instituta eorum pravitas subripiendo principum amimos aliqua sibi iniusta non poposcissent beneficia. Proinde, quia Deo adjuvante legem fieri decrevimus et fraudibus eorum per diversa capitula obstitimus, ideo pro id, quod retro tempore fuerat vitiatum, iuxte edictum antedicti principis decernimus: ut (...)" (Zeumer, 1902, 418)

"Flavio Sisebuto Rey.

A los veneradísimos y santísimos Agapio y Cecilio, asi mismo a Agapio, a los obispos o a los jueces en aquel lugar designados, e igualmente a los demás sacerdotes 0 jueces que se encuentran en los territorios de Barbi, Aurgi, Isturgi, Iliturgi, en Viatia, de Tutugi, en Igabro y en Ipagro. La autoridad de lo decretado hace ya tiempo por nuestro señor y antecesor el Rey Recaredo -que de ninguna manera quedaran los esclavos cristianos sometidos al poder de los hebreos (judios) - podia haber sido suficiente siempre y cuando, granjeándose con su perversidad los corazones de los príncipes contra el decreto impuesto, no hubieran reivindicado después para sí ciertos beneficios injustamente» (Trad. de A. Ibáñez Chacón).

Citada de nuevo en la recopilación que se hace de la misma en el Fuero Juzgo (Lib. XII, Titul. II, XIII) no será hasta el siglo XIX cuando el vocablo Sturgi aparezca en el Diccionario Geografico-Historico de la España Antigua de Cortés y López donde observamos una serie de matizaciones, fruto de compilaciones anteriores cuya base, posiblemente, sea el ingente trabajo de Flórez quien en el tomo XII de su España Sagrada ofrece una disertación muy interesante sobre los topónimos Iliturgi, Isturgi e Ipasturgi (Florez 1776: 358-367).

El punto de partida de la confusión Isturgi e Iliturgi (Fernández Garcia, Ruiz Montes y Peinado Espinosa, e. p.) se originó en el siglo XVII como consecuencia del "hallazgo» en la centuria anterior en la iglesia de Valdemao (Lugo) de los restos de San Eufrasio, primer obispo de lliturgi, lugar que algunos ubicaban, sin ninguna justificación, en Andújar. Dicha noticia llegó a conocimiento del Doctor Juan del Caño, canónigo de León en 1571, quien era originario de la ciudad de Andújar lo que le motivó a intentar promover su culto. La empresa iniciada por Juan del Caño alcanzó su culmen unos años después de su muerte por obra del Doctor Francisco Terrones, sobrino de aquel. Y asi surgió, en el binomio San Eufrasio-Andújar, la errónea interpretación. En relación con ello, conviene matizar la plena aceptación de la relación Isturgi-Los Villares de Andújar tanto en las publicaciones relacionadas con la propia Historia de Andújar (Gómez Martínez 1989: 18; Cruz Utrera 1990: 99-101) como en las referentes a la documentación de carácter arqueológico y epigráfico (Fernández García y Morales de la Cruz 2007 v. anexo I; González Román y Mangas Manjarres 1991), resultando sorprendente que, actualmente, en determinadas publicaciones, foros de Internet y prensa, se siga manteniendo una polémica absolutamente obsoleta que tuvo su origen, nada inocente, en un aspecto puramente religioso como la atribución de unas reliquias, consideradas de dudosa filiación, a un núcleo que las acogió con todo el fervor propio de la época, según se deduce de la hagiografía. San Eufrasio fue objeto de tal devoción que acabó siendo promocionado como Patrón de la ciudad de Andújar cuyo rango ostenta en la actualidad, lo que en absoluto es incompatible con la asunción de la existencia en Los Villares de Andújar de un núcleo romano identificado con la Isturgi citada por Plinio.

Núcleo del que desconocemos los distintos elementos que conformarian sus espacios urbanos, si bien su entidad se intuye por la documentación epigráfica y por los elementos arquitectónicos recuperados, como consecuencia de las labores agrícolas (Jiménez de Cisneros Moreno 2007). De la ciudad no sabemos nada pero sí de una de sus actividades económicas -sus alfares-, de los que estamos en condiciones de asegurar que nos encontramos ante un complejo alfarero de gran envergadura según se desprende de los potentes vertederos excavados hasta el momento y que tan sólo representan una mínima parte de esa producción. En base a los vertederos excavados del corte 14 con sus tres cúmulos y, fundamentalmente, los vertederos excavados de los cortes 21 a 24 con sus importaciones, se pudieron estable- 
cer una serie de puntualizaciones cronológicas referidas a la fase inicial del alfar (Sotomayor Muro, Pérez Casas y Roca Roumens 1976; Roca Roumens 1980).

De las distintas clases cerámicas elaboradas por las diferentes officinae que conformaban el complejo isturgitano, sin duda, la producción de terra sigillata hispánica ha acaparado, mayoritariamente, la atención de la investigación por dos motivos principales. Primero, por cuánto aportaba desde el punto de vista cronológico y, segundo, porque posibilitaba un acercamiento al conocimiento de las estructuras de producción y comercialización del complejo alfarero con todo lo que ello implicaba a nivel de la reconstrucción de la historia social y económica de una zona importante de la Baetica. No obstante, aunque se han tratado con menor intensidad, sin embargo, son objeto en la actualidad de revisión e investigación las producciones de cerámica pintada de tradición ibérica, las paredes finas, las lucernas, las cerámicas de imitación tipo Peñaflor y la cerámica común romana.

El estudio de todas estas producciones $y$, especialmente, de la sigillata hispánica ha permitido establecer importantes secuencias cronotipológicas con todo lo que ello implicaba para los centros receptores en los que se han recuperado e indirectamente por lo que suponía de conocimiento a nivel de difusión de sus productos.

Hoy, después de casi ya cuarenta años de investigación en el yacimiento, con una amplia bibliografía a nivel nacional e internacional, podemos mirar hacia atrás para ver los logros conseguidos y de esta forma avanzar hacia donde el proyecto Isturgi debe, paulatinamente, derivar. En este sentido, la información generada a través de años de continuada investigación, ha permitido precisar la existencia de un importante complejo alfarero del que conocemos una parte de sus estructuras de producción y comercialización.

Respecto a las primeras conviene tener presente que un centro de producción tiene como misión canalizar la actividad realizada por los distintos talleres que lo integran. En este sentido el taller u officina, estaría constituido por un conjunto de artesanos y operarios que trabajarian para un mismo officinator, pudiendo ser éste tanto un dominus de una villa como una persona relevante de una ciudad o un alfarero (Mayet 1984: 17). La actividad del taller o talleres se desarrolla en la dinámica de las estructuras productivas del centro, esto es, en sus estructuras físicas, humanas, legales y económicas (Fernández García 1999).

Bajo la denominación de estructuras físicas de producción se engloban una serie de zonas e instalaciones donde se desarrolla la actividad alfarera: zona de captación de materias primas, zona de tratamiento y almacenaje de la misma, zona de elaboración, zona de secado, zona de cocción, zona de almacenamiento de los productos cerámicos, zona de vertido y zona de habitat del personal (Fernández Garcia 1999:15). En la actualidad conocemos, con las debidas reservas, una parte de los espacios conformadores de las es- tructuras físicas de producción de los alfares isturgitanos. En este sentido, se han localizado las canteras de arcilla situadas en la proximidad del alfar. Igualmente se han descubierto, en las distintas campañas de excavación, una serie de estructuras pavimentales y murarias, de difícil interpretación; consideradas algunas de ellas tradicionalmente como posibles zonas de almacenamiento de las distintas producciones cerámicas (Fernández García 1999; Fernández García et alii 2000). Actualmente se está revisando esta u otra posibilidad, en base al análisis pormenorizado tanto de la documentación de campo como del material que se asociaba a dichos elementos constructivos.

Asimismo se han identificado zonas de cocción con cinco hornos dispersos, cuatro de ellos en campañas de excavaciones y otro en una prospección arqueológica superficial, si bien una serie de indicios permite pensar en la existencia de otro u otros más. Tipológicamente se trata de hornos circulares con la parrilla sostenida por un pilar central y bóveda anular de clara inspiración indígena (Sotomayor Muro Pérez Casas y Roca Roumens: 1976; Sotomayor, Roca, Sotomayor y Atencia 1981; Diario de Excavaciones de M. Sotomayor; Ruiz Montes y Peinado Espinosa e. p.).

Sin lugar a duda, la zona de vertido ha sido, con diferencia, objeto de una mayor atención, proporcionando una importante información, sobre todo desde el punto de vista de las estructuras humanas y también, aunque en menor medida, de las estructuras económicas de producción.

Respecto al componente humano habría que considerar la existencia de un personal experto -el ceramista y el maestro hornero- frente a un contingente más numeroso de trabajadores no especializados que asumirian las distintas tareas que, dentro del engranaje productivo, no necesitaban de una capacitación determinada -extractores de la materia prima, transportistas de la misma, decantadores de la arcilla, redistribuidores de los productos resultantes a los secaderos, hornos o almacenes, entre otros.

Se constata un artesanado especializado en la elaboración de ejemplares lisos y decorados en terra sigillata hispánica. Algunos productores de sigillata hispánica lisa utilizan como recurso decorativo la técnica del burilamiento y de la barbotina sobre sus ejemplares y, en ocasiones, dejan constancia de su trabajo mediante la impresión de su sigillum en el fondo interno del vaso bien epigráfica o anepigráfamente, en este último caso mediante la utilización de las marcas de entalle. Hasta el presente se han evidenciado las siguientes officinae: $A, A A, A H E, C A, C A A, C A H, C L$ ( $L$ arcaica) marca erróneamente leída como $C K, C L, C P F$, CVDAS, DACI, GAA, GCL, GIC, GITR, IC, LA, LC, LCA, LCV, LIA, LPF, MA. MC, MC, MCF, MOV, MPF, MS, MSF, MSM, NA, OPTATVS, P, PE, PM, PF, PT, TIF, TITVS, OPPIVS, VD, VS (Sotomayor Muro, Roca Roumens y Fernández García 1999: Fernández García 2004 a: 256-260; Fernández García, Ruiz Montes, Peinado Espinosa et alii e. p.). 
Respecto a los fabricantes de vasos decorados, de los tres estadios productivos, es decir, fabricantes de punzones, fabricantes de moldes y fabricantes de vasos, en el complejo isturgitano se han constatado las dos últimas categorias. En este sentido los productores de moldes dejan constancia de su trabajo mediante el empleo de marcas epigráficas o anepígrafas tanto en el fondo interno como en la parte externa del molde, es decir, en aquellos lugares donde no aparecen al ejecutar el vaso decorado; los fabricantes de vasos decorados casi siempre intradecorativamente, constituyendo, en algunos casos, auténticos motivos decorativos. Tan sólo siete officinae: MSM, CPF, MTF, CVDAS, OVARTIO, TITVS OPPIVS y OSP han dejado constancia de su trabajo sobre ejemplares decorados, a los que habría que añadir la identificación de nueve estilos anónimos (Fernández García 1998: 2004 a: 251-261; Id. e. p.).

En el complejo alfarero de Los Villares de Andujar se ha documentado por parte de un alfarero que firma su producción como TITI OPPI una doble faceta de productor de molde y de vaso al aparecer su firma tanto en el fondo interno como entre la decoración en dos moldes recuperados con todo lo que ello implica a nivel de reconstrucción desde el punto de vista social y económico (Fernández García 1991-92). En relación con esto último, conviene destacar, en los primeros momentos de fabricación de sigillata hispánica, una asociación de alfareros, patente en varios vasos, materializada por las marcas MSM, CPFy MTF. Si bien las dos últimas siempre van en tria nomina, la primera se distingue de las otras bien por aparecer su tria nomina precedido de la fórmula hispánica EX.OF., por llevar su tria nomina en cartela rectangular o por presentar desarrollado su nombre M(). SATRI MONTANI, pudiendo expresar esa diferenciación una especie de jerarquización ya que sabemos que la officina de MSM es la más importante de la primera época productiva (Fernández García 1988: 356; Fernández García, Ruiz Parrondo y Ruiz Montes 2007).

Poco más podemos discernir acerca de la situación social del artesanado isturgitano, del cual, mediante la lectura de las marcas, se aprecia la inexistencia, hasta el momento, de una mano de obra servil especializada, siendo posiblemente individuos libres los detentadores del sistema productivo. No obstante, estamos revisando (Ibáñez Chacón y Fernández Garcia) toda la problemática generada por los dua y tria nomina recensados así como por el alfarero que firma sus productos como CVDAS, por lo que pueda implicar de latinismo su propia denominación, cara a intentar detectar la asimilación, cuando proceda, por parte del sustrato indígena de ciertas prácticas aportadas por el elemento romanizador.

Una especial referencia merecen las marcas anepígrafas documentadas sobre algunos ejemplares lisos de sigillata. ¿Cuál es su significado? ¿Es el mismo que las documentadas sobre la producción de lucernas y de moldes? ¿Son indicativas de una situación social, de una subordinación dentro de una escala más o menos aceptada dentro de un sistema productivo donde, dada la entidad del mismo, es necesario un control? En el caso de las lucernas, especialmente la firmada con la hoja acorazonada o lanceolada, objeto de un importante comercio ¿Tendrían el mismo valor en el mercado que las lucernas firmadas por MCS (retro)?

Aunque de momento no obtengamos respuestas lo cierto es que todo debía estar programado, más o menos, al detalle ya que estas instalaciones alfareras movían un variado y gran volumen de productos cuya salida al mercado, con todo lo que ello implica de gastos, pérdidas y ganancias, exigía un gran esfuerzo de planificación (Fernández García 2004a: 267-268), en el que desempeña un papel de primer orden las estructuras económicas de producción.

A diferencia de lo que sucede en otros centros productores extrapeninsulares donde se han podido establecer unos sistemas económicos en torno a los cuales gravitaría la articulación de las figlinae, para el caso hispano y, concretamente, para los talleres isturgitanos la reconstrucción de su funcionamiento es difícil. No obstante, al menos contamos con un índice económico controlador de un aspecto del sector productivo constituido por las denominadas probinas, es decir, una serie de fragmentos en terra sigillata hispánica caracterizados por presentar esquinas redondeadas o alargadas que podian ser totalmente lisos o bien decorados y cuya impronta se obtenía mediante un vaso decorado o un molde; en ocasiones las probinas tanto lisas como decoradas van acompañadas de una inscripción. A estos fragmentos se les denominó probinas al considerarlas en un principio como posibles pruebas de punzones, o para la consecución de buena calidad del barniz, de las condiciones del horno, etc. (Roca Roumens y Fernández García 1987-88; Roca Roumens 1976: n. ${ }^{\circ}$ 247). Esta interpretación la hemos mantenido hasta 1999 cuando en el vertedero explorado del corte 30, se documentaron más de sesenta probinas, de las que destacaré, entre otras muy interesantes, tan sólo un ejemplar liso con la inscripción OVART alusiva a QVARTIO, alfarero adscrito a la primera época productiva en la fabricación de sigillata hispánica. Posiblemente mediante el empleo de su marca sobre una probina lisa dejaba constancia de la introducción de sus productos en el horno, individualizándolos de los otros alfareros que compartían con él la misma hornada. Nos encontramos, con las debidas reservas, ante un posible control de la producción materializado en las probinas (Fernández García y Morales de la Cruz 2007). Un control, al menos aparentemente, no tan minucioso como el constatado en el complejo alfarero sudgálico de La Graufesenque, donde gracias a los grafitos recuperados y en especial al 25B todos los aspectos relativos a la producción y comercialización de los ejemplares cerámicos estaba perfectamente controlado y, donde queda patente que, entre los años 40 y 95, una serie de alfareros, cuyo número variaba, se asociaron en lo que se ha denominado organización mancomunda con objeto de producir la cantidad de va- 
sos necesarios que les permitieran grandes hornadas en las que tendrían cabida 40.000 ejemplares (Marichal 1974 1986; Bémont y Vernhet 1989: 44). Con los datos actuales no podemos estimar el número de ejemplares que se introducirían en los hornos del complejo isturgitano, si bien el registro arqueológico, evidencia que, en una misma hornada, varios eran los alfareros que depositaban sus vasos para ser cocidos como lo demuestran las probinas exhumadas.

Resulta complejo discernir el sistema por el cual se regirian los talleres isturgitanos, aunque parece inferirse, para los primeros momentos de la fabricación de la terra sigillata hispánica, ciertos indicios de jerarquización por parte de la officina de MSM (M... SATRVS MONTANVS) no sólo patente en su manera de firmar con sus asociados CPFy MTF en los que parece dejar claro su papel de prioridad, sino también en el uso común de punzones con otros alfareros como OVARTIO y CVDAS, todos ellos adscritos a la primera generación productora de sigillata hispánica -época julio-claudia. Generación ésta que se caracteriza por un variado repertorio formal de la terra sigillata, con claros prototipos en el mundo itálico así como en el repertorio ibérico, a los que hay que añadir algunas imitaciones de vasitos de paredes finas; influjos, a su vez, patentes en algunos recursos decorativos. En general, los ejemplares muestran una buena calidad de pasta, barniz y decoración, estando esta última constituida por composiciones, muy cuidadas, caracterizadas un variado repertorio de motivos y/o temas. Se adscribe a esta fase la actividad de los alfareros MSM, CVDAS, CPF, OVARTIO, OSP y MTF, así como el sexto, séptimo y octavo estilo anónimo, trabajando los tres primeros artesanos tanto las formas lisas como las decoradas. Sus productos se constatan con profusión en el Norte de Africa lo que no impide una difusión de sus productos en un ámbito más cercano. Junto a la terra sigillata se fabricó intensamente cerámica pintada de tradición ibérica, cerámica común romana, paredes finas y lucernas, existiendo, a la vez, indicios de elaboración de platos de engobe interno rojo pompeyano y cerámica de imitación (Fernández García, 1988; 2004 a).

Ese control del sector productivo por parte de officinae tipo MSM, desaparece en la segunda generación de alfareros productores de sigillata hispánica -época flavia-donde hay una proliferación de talleres que firman la producción de vasos lisos ( $A, A A, A H E, C A$, etc.). Asimismo es significativo la ausencia, hasta ahora, de ejemplares decorados con marcas alusivas a sus fabricantes mientras que asistimos a una valoración de los fabricantes de moldes como queda demostrado por la presencia de sus marcas, epigráficas o anepígrafas, fundamentalmente en el fondo interno aunque se constatan también bajo la decoración y en la parte externa del molde, lugares donde no pueden ser reproducidas al confeccionar el vaso decorado y, por tanto, totalmente indicativas de los fabricantes de moldes. No hemos de olvidar que los auténticos responsables de una buena decoración son los fabricantes de punzones y después los fabricantes de moldes quienes dispondrán los distintos motivos y/o temas que han de componer la sintaxis decorativa del vaso; por tanto el papel del fabricante del vaso decorado se reduce a su correcta ejecución tras la introducción de la pella de arcilla en el molde y el torneamiento del ejemplar. En un momento en que la demanda generalizada de productos es amplia, no parece descabellado que se produzca una "revaloración» de los fabricantes de moldes como responsables directos, en cierto aspecto, de la producción decorada. Posiblemente en este contexto deba encuadrarse la actividad de TITVS OPPIVS, alfarero puente entre la primera y segunda generación, que firma la producción lisa y del que tenemos constancia, a su vez, de su doble faceta como fabricante de moldes y de vasos decorados, quizá debido más a una necesidad que a un deseo, motivada por mantener cierta preponderancia en el sector productivo cuando las viejas estructuras jerárquicas por imperativos de la demanda del mercado van desapareciendo. Asistimos, pues, en esta segunda generación a una transformación en las estructuras productivas motivada posiblemente por la demanda de estos productos en unos mercados donde "todo vale, todo se vende, todo tiene un público determinado" y al decir "todo" se incluyen vasos que, en condiciones normales, jamás habrian sido objeto de comercio. Fenómeno constatado en el centro sudgálico de La Graufesenque donde, en torno a los años cuarenta de la era, dicho centro sufre también una transformación de sus estructuras productivas observándose, como se ha indicado, indicios de una organización mancomunada (Delplace 1978: 66-70; Nieto $1986: 109 ;$ 1987). Cabe preguntarnos si esto que se observa en La Graufesenque es un hecho aislado o por el contrario es un "hecho común" que paulatinamente irá llegando a los centros productores hispanos de cierta entidad, lo que supondría un cambio en todo caso posiblemente motivado por las propias estructuras de mercado y que, evidentemente, lleva aparejado importantes cambios sociales y económicos (Fernández García 2004 a: 268).

En esta segunda generación de productores de sigillata el repertorio formal se simplifica asistiendo a una repetición con pocas variantes de las formas clásicas. La sintaxis decorativa tiende, en general, a hacerse monótona a base de composiciones poco creativas y en algunos ejemplares se evidencia un abandono de la estética al adoptar motivos de gran tamaño en composiciones poco acertadas, a la vez que la impresión de los punzones es cada vez más descuidada y descentrada. La producción de cerámica común romana sigue siendo intensa en época flavia, tendiendo a decrecer, dentro de la misma posiblemente en favor de la terra sigillata. Junto a la cerámica común se sigue fabricando cerámica de tradición ibérica y paredes finas, cuya producción decrece sensiblemente. Es una generación en la que se documenta una intensa difusión de sus productos en la Bética, en el Norte de África y en otros puntos peninsulares. Coincidien- 
do con la expansión de sus productos se constata, en esta época flavia, la creación de una serie de talleres de menor difusión dependientes, al menos, en los primeros momentos del centro isturgitano.

A la tercera generación productora de sigillata hispánica -siglo II- se adscribe la actividad de una serie de alfareros, algunos de los cuales dejan constancia de su trabajo mediante el empleo de las marcas de entalle. Los ejemplares recuperados muestran una pésima calidad tanto de pasta, barniz como de decoración en relación con las etapas precedentes. Es una producción en la que se hace patente un abandono de la estética tanto en el repertorio liso con formas macizas y pesadas como en el decorativo con una mezcolanza de motivos poco cuidados, en muchos casos inidentificables. Quizá este abandono de la estética, en general, sea debido a la competencia en el mercado de otras producciones, como algunas africanas $A$, de tal manera que los alfareros elaboran, a partir de entonces, sus productos más para un comercio de tipo "regional» o local que a gran escala, lo que, junto posiblemente a otras causas que desconocemos, pudo originar la paulatina perdida de influencia de estos productos en los circuitos de mercado (Roca Roumens y Fernández García 1988).

No sabemos si esa pérdida de mercados llevaría implícito una reducción del espacio alfarero del que, en función de la descripción de los restos emergentes visibles en los siglos XVII y XIX (Fernández García, Ruiz Montes y Peinado Espinosa, e. p.) parece deducirse su posible inserción intramuros. De ser cierto, realmente constituiría una especie de barrio artesanal determinado por la existencia de actividades artesanales cuya identificación quedó prácticamente definida desde el comienzo de los trabajos de campo en el yacimiento (Sotomayor 1972: 264-265; Roca Roumens 1976: 11; Ruiz Montes 2007).

Un complejo artesanal cuyos productos se canalizaban mediante los mecanismos al uso insertos dentro de las estructuras de comercialización, en la que los factores humanos y económicos de producción desempeñaban un papel primordial, ya que debian posibilitar una serie de condicionamientos, mediante los cuales, la difusión a corta o larga distancia de sus artículos debían quedar, en cierta modo, garantizada y, por tanto, controlada. Para tal consecución era necesario contar con un componente humano de comercialización, unas infraestructuras viarias, unos mercados y, en ocasiones, con unas sucursales. Unas estructuras comerciales de producción que pueden permitir, además, de la reconstrucción de los posibles circuitos del complejo alfarero -terrestre, marítimo o fluvial-, una aproximación a la difusión de sus productos - corto y/o largo alcance-, el establecimiento, en algunos casos, de sucursales vinculadas en sus inicios al centro madre, así como la capacidad de imposición al mercado a lo largo de la vida activa del alfar pequeña, mediana o gran difusión en todas o en algunas de sus fases productivas (Fernández García 1999).
La entidad de los talleres isturgitanos queda manifiesta en la difusión a corto, medio y largo alcance de sus productos, de una u otra forma, incluidos en los circuitos de mercado. La necesidad de aprovisionar a un sector demandante de sus artículos propició, como antes se ha dicho, la creación de una serie de talleres de menor difusión conectados con el momento álgido de la producción de Andújar, época flavia. En las actuales provincias de Granada y Málaga se han descubierto un total de seis sucursales, dos en la primera y cuatro en la segunda, si bien éstas no debieron de ser las únicas ya que su implantación se corresponde con un momento de expansión en los mercados de las producciones de terra sigillata en general, y de la hispánica en particular, facilitando de esta forma, más rápida, su llegada al mercado "regional» con la consiguiente disminución del gasto que, en principio, originaría, el suministro desde el centro madre. En el estado actual de nuestros conocimientos no estamos en condiciones de afirmar si se trata realmente de sucursales de Andújar o bien de pequeños talleres, independientes, creados inicialmente por alfareros del centro isturgitano.

La vinculación de los talleres granadinos a los isturgitanos queda patente en determinados aspectos del prontuario formal y de la sintaxis decorativa, extensible no sólo a la sigillata hispánica sino también a otras clases cerámicas. En el caso del alfar situado en el Carmen de la Muralla ubicado en el granadino barrio del Albaicín destacar junto a esos influjos la presencia de la marca $L M F$, documentada en Los Villares de Andújar. Taller éste creado en un momento avanzado de época julio-claudia o principios de la flavia, que satisfacía una demanda de carácter local y regional cuyos productos se han localizado, hasta el momento, en las proximidades de Ilurco-Pinos Puente, Granada- o en el más lejano pasillo de Fiñana (Almería). Este alfar debió actuar conjuntamente con el otro granadino localizado en Cartuja, al menos por un corto espacio de tiempo hasta el establecimiento final, en un momento no muy avanzado de la segunda mitad del siglo I, de la actividad alfarera en la zona cartujana. Con esta definitiva ubicación se facilitaba mejor el aprovisionamiento de los recursos propios del alfar y una salida más directa de su producción hacia los mercados a la vez que, posiblemente, permitía una ampliación del complejo alfarero sin demasiados problemas. Aunque algunos indicios - presencia de formas Aj. 1 flavias y determinados ejemplares decorados- evidencian el inicio de la cronología del taller cartujano en momentos cercanos de la segunda mitad del siglo I, su pleno funcionamiento se situaría en torno al tercer cuarto del siglo I, avalado por la sigillata gala recuperada y por la marca EX OFCA, perteneciente a un alfarero de la segunda generación de Los Villares de Andújar. En relación con su extinción, aunque contamos con pocos datos, parece que podía situarse en momentos no muy avanzados del siglo II. La difusión de sus productos fue puramente local documentándose restos en Ilurco y en la zona territorial de Tutugi - 
Galera, Granada-, si bien no debe descartarse el hallazgo en otros puntos de la actual provincia granadina (Fernández García 1997; 2004b; Fernández García y Ruiz Montes 2005).

En la década de los ochenta el conocimiento sobre los alfares del sur peninsular se incrementó con la inclusión de tres centros localizados en la provincia de Málaga - Singilia Barba, Antikaria y Alameda- a los que habrá que añadir un cuarto - Teba- a principios de la década de los 90, con una conexión muy evidente con el complejo alfarero de Los ViIlares de Andújar (Atencia Paéz y Serrano Ramos, 1997; Fernández García y Ruiz Montes, 2005, Roca Roumens, 1994; Serrano Ramos, 1986; 1988; 1991; 1997; 1998; 1999; 2004).

De todos ellos, el alfar singiliense revela no sólo una conexión directa con el complejo isturgitano sino también con el granadino del Carmen de la Muralla materializado en unas manufacturas que gravitarían en la órbita de la officina de $L M F$, caracterizada por el empleo de unidades mínimas decorativas de estructuración triangular muy peculiares (Fernández García e. p.).

En general los talleres malagueños estuvieron en funcionamiento desde mediados del siglo I a mediados del II. Sus productos, a tenor de lo documentado, no parecen que tuvieran una amplia difusión. En este sentido, destacar la presencia de ejemplares singilienses en el Cerro de los Castillones de Campillos, en diversos yacimientos de la zona de Antequera y en el Valle de Abdalajís. El resto de los alfares tuvieron, aún, una menor difusión ya que ejemplares antikarienses sólo se han documentado en una villa en Benalmádena, y los talleres de Alameda y Teba en las Termas de Santa María en Antikaria si bien ejemplares tebanos se han documentado también, en la villa romana de los Castillones de Campillos.

\section{FUTURO DE LAS INVESTIGACIONES EN EL COMPLEJO ISTURGITANO}

El yacimiento sobre el que se asentaba la antigua Isturgi posee un valor excepcional para el desarrollo de una investigación sistemática ya que, por una parte, tenemos la ciudad esperando ver la luz y, por otra, se conservan los vertederos, los hornos así como los restos de las instalaciones propias de un alfar de la importancia del que estamos tratando.

Hasta ahora la investigación se ha centrado prioritariamente en la zona de vertido y de las distintas clases cerámicas elaboradas en el alfar se ha dedicado una especial atención a la terra sigillata hispánica, lo que ha permitido, a lo largo de estos treinta y ocho años, establecer importantes secuencias cronotipológicas con todo lo que ello implicaba para los centros receptores en los que se han recuperado.

Empezamos a conocer como funcionaban los talleres isturgitanos en la primera fase de producción de sigillata -época julio-claudia-, cuando sus estructuras de produc- ción y comercialización, en cierto aspecto, están formadas y se consolidan, de una u otra forma, al insertarse en la órbita de las corrientes contemporáneas al uso. Sin embargo, desconocemos cómo se produce su punto de inflexión con respecto a la etapa precedente cuyo componente humano debió desempeñar, sin lugar a dudas, un papel fundamental en un proceso transformador que llevaba aparejado una serie de cambios estructurales, cambios en todo caso no traumáticos como parece evidenciarse, entre otros, por la presencia de esos hornos de tradición indígena aunque adaptados a las exigencias tecnológicas que los nuevos productos demandaban. En relación con ello, por tanto, se hace necesario profundizar y hacer hincapié en el momento anterior al de esta primera producción de sigillata al objeto de comprender este proceso de cambio posiblemente motivado por la propia de dinámica del mercado en el que la creación de la Vía Augusta influirá notablemente. Momento, por otra parte, algo conocido por algunas evidencias puntúales -cúmulo 1 del corte 14, entre otros.

Es cierto que desconocemos la antigua Isturgi, ciudad que se nos revela, cada vez más, con una cierta entidad a tenor de los restos recuperados como consecuencia de los trabajos agrícolas y que, en cierta medida, corroboran la importancia del enclave ya intuida a partir de la información suministrada por la Epigrafía. Asentamiento del que desconocemos absolutamente todo lo referente a los elementos integrantes de los distintos espacios urbanos y cuyo conocimiento sería de suma importancia para la propia comprensión de su génesis.

Por tanto, dos son las vertientes prioritarias de investigación; por una parte, intentar comprender el sustrato indígena y sus manufacturas con todo lo que ello implica tanto de continuismo como de asimilación y, por otra parte, una aproximación a la realidad urbana que nos permita ofrecer nuevos elementos de valoración para entender los asentamientos indígenas ante la romanización en su dimensión material, por ejemplo, la monumentalización. En este sentido es necesaria la caracterización del núcleo que articula el territorio y, por tanto, todas las actividades económicas que en él se desarrollan con lo que implica, igualmente, de proyección económica.

Teniendo en cuenta estas premisas los objetivos de futuro han de canalizarse en dos direcciones: investigación del núcleo urbano y de las actividades artesanales.

\section{EL NÚCLEO URBANO}

Es necesario conocer Isturgi y su entorno. Dentro de esta dinámica habrá que considerar su valoración y su evolución como un importante núcleo urbano de época romana; ello será posible mediante la conjunción de los datos suministrados por las distintas técnicas arqueológicas que se uti- 
lizarán en el futuro en el desarrollo del proyecto, sin olvidar la aportación de la documentación escrita. Si bien la principal fuente suministradora de información serán las intervenciones arqueológicas, el proyecto Isturgi se insertará, como ya viene sucediendo, en una investigación global encaminada a la obtención de un conocimiento de conjunto global que posibilite unas líneas de estudio generadoras de discernimiento científico. En este sentido, dado nuestro papel de historiadores debemos tener presente dos variables prioritarias: el espacio y el tiempo del hecho histórico-arqueológico que determinará el proceso romanizador, a nivel urbanístico, monetario, social, económico, etc. en la zona micro espacial donde se produce - Isturgi- que, a su vez, se integra en una entidad de carácter semi macro espacial - Baetica- inmersa en una macro unidad que es la constituida por el poder del imperio de Roma. La comprensión de Isturgi como ciudad pasa, por tanto, por su consideración no sólo como importante lugar de producción sino también de gestión y de vertebración de un territorio.

Dos ejes marcan, por tanto, la actuación en este sector; uno, tendente a la delimitación de los espacios del municipium al objeto de determinar los diferentes ambientes que conformarían este núcleo urbano para intentar aislar, en la medida de lo posible, las áreas artesanales entendiendo como tales no sólo aquellas destinadas al procesamiento del material cerámico sino también, posiblemente, actividades metalúrgicas propias de un asentamiento con una tradición artesana, de relativa importancia, anterior a la llegada de los romanos.

Un segundo eje encaminado hacia el conocimiento de la ciudad en sí. Si bien algunas de las parcelas sobre las que se extiende el núcleo urbano presentan un fuerte nivel de arrasamiento, en otras es posible la recuperación de los espacios representativos de la nueva realidad que el sustrato autóctono acepta con todo lo que ello implica a nivel espacial. No cabe duda que es necesario establecer las características de la romana Isturgi en sus aspectos urbanísticos y arquitectónicos especialmente en época altoimperial así como investigar las transformaciones que la ciudad tuvo que experimentar como consecuencia de su municipalización y que, seguramente, debieron traducirse en la realización de programas edilicios no exentos de cierta monumentalidad como dejan entrever los hallazgos arquitectónicos aislados.

\section{LA ACTIVIDAD ARTESANAL}

Es necesario la continuidad de la investigación en la zona del alfar -aunque no es la única actividad artesanal- con objeto de profundizar en el conocimiento del desarrollo del complejo, desde sus orígenes hasta su plena incorporación al modo de producción romano. En relación con ello, hay que actuar en dos frentes. Uno consistente en el análisis de la fa- se de transición entre las producciones de época prejulioclaudia y las producciones de tipo romano de época julioclaudia. En este sentido destacar, como han señalado algunos investigadores, la evidencia en muchos asentamientos hispanos, en momentos plenamente romanos, de la pervivencia del elemento indígena materializado en la transformación de antiguas tradiciones a través de la adopción de nuevas costumbres. Hecho éste que puede observarse en los productos cerámicos en la medida en que se copian o reproducen ejemplares que llevan implícitos, asimismo, unos hábitos de consumo ajenos al mundo indigena. Imitaciones en las que, de una u otra manera, están presentes una serie de aspectos relacionados con ese mundo autóctono originando, en ocasiones, creaciones un tanto particulares. En los últimos años se documentan, en torno al valle del Guadalquivir y sus afluentes, estas producciones a las que conviene caracterizar cronotipológica y tecnológicamente para su correcta comprensión. Por ello, será de importancia primordial la observación, en centros productores y receptores béticos, del comportamiento de la vajilla indígena y el influjo del gusto itálico sobre ella. En relación con ello, los alfares de Andújar podrán aportar una notable información, como se ha indicado, a partir de ciertos indicios proporcionados por la exploración de algunos de los vertederos (cúmulo 1 del corte 14, entre otros).

Asimismo conviene observar la incidencia de la producción de los alfares de Isturgi a nivel local y regional evaluando el impacto de todas las clases cerámicas producidas en época prejulio-claudia y julio-claudia con la finalidad de establecer facies cerámicas que manifiesten la importancia del factor indígena frente al romano permitiéndonos acercarnos al nivel de romanización de esa sociedad beneficiaria y consumidora de dichos productos.

Un segundo frente de actuación en la investigación de los alfares isturgitanos lo constituye la profundización en el conocimiento de la producción de época julio-claudia y flavia. Actualmente con los datos disponibles ha sido posible caracterizar la producción de estas fases, cada una de ellas con una problemática muy particular que, probablemente, refleja concepciones distintas en la gestión de la producción y comercialización de los productos de este alfar. Fases en las que hay que continuar profundizando al objeto de llegar a una reconstrucción de sus estructuras humanas y económicas de producción con lo que ello conlleva, a su vez, de plasmación, entre otros, en los circuitos de mercados.

Por último, teniendo en cuenta las distintas categorias cerámicas producidas en los alfares isturgitanos a lo largo de su vida activa, se ha procedido y se procederá en fechas próximas a su correcta caracterización desde el punto de vista arqueométrico, para establecer la correcta atribución de los mismos $y$, en consecuencia, poder formular reflexiones en términos de historia económica -distribución y comercialización. 
A través de esta síntesis se intuye que en el yacimiento isturgitano pasado, presente y futuro investigador constituye un unicum sin solución de continuidad, lo que ha posibilitado una serie de líneas de investigación que se canalizarán en dos grandes objetivos de futuro: núcleo urbano y actividades artesanales.

Antes de finalizar quisiera enfatizar que el acercamiento a la realidad isturgitana sólo ha sido posible, como lo será en un futuro, gracias a un arduo trabajo en equipo, principio fundamental que supieron transmitirnos los maestros M. Sotomayor y M. Roca de quienes aprendimos no sólo a investigar nuestro Patrimonio sino a apreciarlo, como si fuese parte consustancial de nuestro ser. A ellos, pues, quienes mediante su trabajo, esfuerzo y tesón nos abrieron el camino para poder continuar con su labor quisiera dedicar con la mayor admiración, respeto y cariño, tanto en mi nombre como en el de mi equipo, el presente y el prometedor futuro de las investigaciones en el complejo alfarero vinculado a la antigua Isturgi -Los Villares de Andújar.

NoTA. La redacción del presente trabajo ha contado con el soporte del proyecto Ciudad y tradiciones productivas: comercio, distribución y consumo (HUM2007-64460/HIST) enmarcado dentro del Plan Nacional de Proyectos I+D 2007.

\section{BIBLIOGRAFÍA}

Atencia Paéz, R. y Serrano Ramos, E. 1997: «El taller Antikariense de terra sigillata hispánica", Figlinae Malacitanae. La producción de cerámica romana en los territorios malacitanos, 177-215.

Bémont, C. y Vernhet, A. 1989: «Les potiers de La Graufesenque. Four coIletif et organisation de production dans un village", Le Courrier du Centre National de la Recherche Scientifique, 73: 44-46.

CRUz UtRERA, J. 1990: Arqueología de Andújar. Torredonjimeno.

DelPLACE, CHR. 1978: "Les potiers dans la société et l'économie de l'Italie et de la Gaule au I siècle av. et au I sècle ap. J. C.n, Ktema, 3: 55-76.

Fernández García, Ma I. 1988: Los diversos estilos decorativos de la sigiIlata hispánica de Andújar. Granada (microfichas).

- 1991-92: «TITI OPPI y la segunda generación de alfareros e Los ViIlares de Andújar (Jaén)", Cuadernos de Prehistoria de la Universidad de Granada, 16-17: 401-413.

- 1997: «Notas acerca de la Terra Sigillata Hispánica del alfar del Carmen de la Muralla (Albaizin, Granada)", Florentia lliberritana, 8: 85-101.

- 1998: "Características de la sigillata fabricada en Andújar» en Fernández García, Mª I. (Ed.), Terra Sigillata Hispánica: estado actual de la investigación. Jaén: 49-104

- 1999: Breve introducción al estudio de la terra sigillata.l. Estructuras de producción y comercialización. Centro de Estudios Universidad y Progreso. Andújar.

- 2004a: "Alfares y producciones cerámicas en la provincia de Jaén. Balance y perspectivas», en Bernal, D. y Lagostena, L. (Eds.) Figlinae Baeticae. Talleres alfareros y producciones cerámicas en la Bética romana (SS. II a.C.- VII d.C.). British Archeological Reports. International Series 1266, 0xford: 239-272.

- 2004b: "Alfares y producciones cerámicas en la provincia de Granada. Balance y perspectivas", en Bernal, D. y Lagostena, L. (Eds.) Figlinae Baeticae. Talleres alfareros y producciones cerámicas en la Bética romana (II a. C.-VII d. C.). British Archeological Reports. International Series 1266, Oxford: 195-238.

- (min.): «Decoración y conceptualización. Una propuesta metodológican, CVDAS, revista de Arqueología e Historia 9-10.

- et alii 2000: "El centro de producción de terra sigillata hispánica de Los Villares de Andújar (Jaén): continuidad de un proyecton, CVDAS, revista de Arqueología e Historia 1: 45-68.

Fernández Garcia, M I. y Ruiz Montes, P. 2005: "Sigillata hispánica de origen béticow en Roca Roumens, M. y Fernández García, Mª I. (Coords.) 2005: Introducción al estudio de la cerámica romana. Una breve guía de referencia, Universidad de Málaga: 139-182.

Fernández Garcia, M I.; Ruiz Parrondo, A. y Ruiz Montes, P. 2007: «Indicios de Jerarquización en la primera época productiva del complejo alfarero de Los Villares de Andújarn, CVDAS, revista de Arqueología e Historia 3-4: 59-71.
Fernández Garcia, M* I. y Morales de la Cruz, M. 2007: «Hacia una estructuración de la producción en el complejo alfarero de Los Vi\|lares de Andujar (Jaén). Nuevos datos aportados por las probinas", CVDAS, revista de Arqueología e Historia 5-6: 45-64.

Fernández Garcia, M I., Ruiz Montes, P. y Peinado Espinosa, M. V.: “De Isturgi et lliturgi confusione», Anales de Arqueología Cordobesa 20.

- et alii: "Figlina Isturgitana», Rei Cretariae Romanae Favtores Acta 40.

Flórez, H. 1776: España Sagrada Teatro Geographico-Historico de la Iglesia de España. Origen, Divisiones, y Limites de todas sus Provincias. Antigüedad. Traslaciones, y estado antiguo, y presente de sus Sillas, en todos los Dominios de España y Portugal, con varias Disertaciones criticas. Tomo XII. De las Iglesias Sufraganeas Antiguas de Sevilla: Egabro, Elepla, Eliberi,Italica, Malaga, y Tucci. Madrid.

Gómez Martínez, E. 1989: Aproximación a la Historia de Andújar. Ayuntamiento de Andújar.

González Roman y Mangas ManjarRés J. 1991: Corpus de Inscripciones Latinas de Andalucía (Volumen III, Jaén), Consejería de Cultura. Sevilla.

Jiménez de Cisneros Moreno, MA. 2007: «Elementos arquitectónicos del "Municipium Isturgi Triumphale», CVDAS, revista de Arqueología e Historia 5-6: 89-100.

MARICHAL, R. 1974: "Nouveaux graffites de La Graufesenque IV", Révue Etudes Anciennes, LXXVI, 3-4: 267-277.

- 1986: «Nouveaux aperçus sur la vie et la structure des ateliers de La Graufesenque d'après les comptes de potiers", La terre sigillée gallo-romaine, Documents d'Archeologie Française 6: 17-20.

MAYET, F. 1984: Les céramiques sigillées hispániques. Contribution à I'histoire économique de la Péninsule lbérique sous l'Empire Romain, vols. I y II. Paris.

MAYHOFF, C. 1906: C. Plini Secundi Naturalis Historiae libri XXXVII, vol. I: libri I-VI. Leipzig.

Nieto, J. 1986: «El pecio Culip IV:observaciones sobre la organización de los talleres de terra sigillata de La Graufesenquen, Archeonautica, 6: 81-119.

- 1987: "Culip IV: consideraciones sobre la comercialización de la terra sigillata de La Graufesenquen, Jornades Internacionals d'Arqueologia Romana, Homenatge a Josep Estrada i Garriga (Granollers, 1987): 426-434.

Roca Roumens, M. 1976: Sigillata hispánica producida en Andújar, Jaén.

RoCA ROUMENS, M. 1980: "Sigillata importada y nuevas formas en terra sigillata hispánica producidas en Andújar. Puntualizaciones cronológicas referidas a la actividad inicial del alfarn, Cuadernos de Prehistoria de la Universidad de Granada, 5: 237-274.

- 1994: "Artesanos y producción cerámica en el Alto Guadalquivir» en González Román ,C. (Ed.): La Bética en su problemática social, Universidad de Granada: 409-424.

Roca Roumens, M. y Fernández García, M`I. 1987-88: «Probinas: ensayos de fabricación de sigillata en el centro de producción de Los Vi\|lares de Andújar (Jaén)», Cuadernos de Prehistoria de la Universidad de Granada 12-13: 205-230 
- 1988: "Algunas consideraciones acerca del comercio entre la Península Ibérica y el Norte de Africa en base a la sigillata hispánica y la sigillata clara An, Congreso Internacional sobre El Estrecho de Gibraltar (Ceuta, 1987): 977-981.

RUIZ MONTES, P. 2007: «Índices de indigenismo y romanización en el complejo artesanal de Los Villares de Andújar (Jaén)", CVDAS. Revista de Arqueología e Historia 5-6: 101-145.

Ruiz Montes, P. y Peinado Espinosa, M V. e. p.: "Los hornos romanos de la provincia de Jaén: el caso de Los Villares de Andújarn, Rei Cretariae Romanae Favtores Acta 40.

SerRano Ramos, E. 1986: "Un nuevo estilo decorativo en la TSH de E Castillón, Antequera (Málaga)», Baetica 9: 247-51.

- 1988: "Singilia Barba, una ciudad de la Bética", Congreso Internacional sobre El Estrecho de Gibraltar (Ceuta, 1987): 821-831.

- 1991: Terra sigillata hispánica de los alfares de Singilia Barba. Málaga.

- 1997: "La producción de TSH del taller de "La Fábrica", Teba, Málagan, Baetica 19 (I): 443-464

- 1998: "Centros productores de terra sigillata hispánica en los territorios malacitanos» en Fernández García, Ma I (Ed.), Terra SigiIlata Hispánica: estado actual de la investigación, Univ. Jaén: 165-188.
- 1999: "Centros productores de TSH en las provincias de Granada y Málaga» en Roca Roumens, M. y Fernández García, Ma I. (Coords.) Terra Sigillata Hispánica. Centros de fabricación y producciones altoimperiales, Univ.de Jaén/ Univ. de Málaga: 137-168.

- 2004: «El taller de terra sigillata hispánica de Alameda (Málaga)», Baetica 26: 9-33

SOTOMAYOR MURO, M. 1972: «Andújar, centro de producción y exportación de sigillata a la Mauritania", Noticiario Arqueológico Hispánico. Arqueología 1: 263-289.

Sotomayor Muro, M.; Pérez CASAs, A. y Roca Roumens, M. 1976: "Los alfares romanos de Andújar (Jaén). Dos nuevas campañas», Noticiario Arqueológico Hispánico, Arqueología 4: 113-147.

Sotomayor Muro, M.; Roca Roumens, M.; Sotomayor, N. y Atencia Páez, R. 1981: "Los alfares romanos de Los Villares de Andújar (Jaén). Campaña 1978-1979", Noticiario Arqueológico Hispánico 11: 309-368.

Sotomayor Muro, M.; Roca Roumens, M. y Fernández Garcia, MI. 1999: "Centro de producción de Los Villares de Andújar (Jaén)» en Roca Roumens, M. y Fernández García, M I. (Coords.) Terra Sigillata Hispánica. Centros de fabricación y producciones altoimperiales, Univ.de Jaén/ Univ. de Málaga: 19-60.

ZEUMER, K. 1902: Monumenta Germaniae Historica, tomus I: Leges Visigothorum. Hannover-Leipzig. 
